\title{
Cómo las fuentes gubernamentales se cuelan en los infográficos de los medios impresos
}

\author{
María Luisa OTERo LóPEZ \\ Universidad de Santiago de Compostela \\ mluisa.otero@usc.es \\ Xosé LóPez GARcía \\ Universidad de Santiago de Compostela \\ xose.lopez.garcia@usc.es
}

Recibido: 08/03/2012

Aceptado: 03/05/2012

\begin{abstract}
Resumen
Las fuentes son un aspecto determinante en el transcurso de la labor periodística. Son el origen de la mayor parte de los productos informativos y suponen, a través de su identificación explícita, una garantía de que se ha desarrollado el proceso de verificación que permitirá construir la noticia. Los gráficos, que ya están incorporados a las páginas de los periódicos, son relatos que también comienzan con algún dato facilitado por una persona, institución o documento, tanto tradicional como digital. La caracterización de las fuentes infográficas era el objetivo. El resultado, un marcado carácter gubernamental/público de las mismas y una presencia importante de fuentes internacionales.
\end{abstract}

Palabras clave: agenda-setting, fuentes, noticias, infografía, periodismo, información

\section{How Government Sources Slips into Newspapers Infographics}

\begin{abstract}
The sources are a crucial aspect in the course of the journalistic work. They are the origin of most of the informative products and, through their explicit identification, they are a guarantee of development of the verification process. Graphics, which already are incorporated into the pages of newspapers, are stories that begin in some data provided by a person, institution or document, both traditional and digital. The characterization of graphic sources is the objective. The result, a marked character governmental and an important presence of international sources.
\end{abstract}

Keywords: Agenda-Setting, Source, News, Graphics, Journalism, Information

Referencia normalizada

OTERO LÓPEZ, María Luisa y LÓPEZ GARCÍA, Xosé (2012): “Cómo las fuentes gubernamentales se cuelan en los infográficos de los medios impresos”. Estudios sobre el mensaje periodístico. Vol. 18, núm. 1, págs.: 173-192. Madrid, Servicio de Publicaciones de la Universidad Complutense.

Sumario: 1. Introducción. 2. Entorno y referencias teóricas. 3. Apuntes metodológicos. 4. La gramática de los infográficos y sus fuentes. 5. Las fuentes en la infografía. 6. Fuentes y contenidos. 7. Conclusiones. 8. Referencias bibliográficas

\section{Introducción}

La aparición del periódico estadounidense USA TODAY cambió la forma visual de los medios de comunicación impresos, creando un modelo imitado en todo el mundo. El color, los snapshots, el mapa del tiempo y la cabecera fueron sus señas de identidad, rasgos que han influido notoriamente en muchas de las transformaciones que ha experimentado la prensa en todo el mundo a partir de 1982. El auge y expansión de las construcciones gráficas ha estado marcada por la tecnología. La capacidad de difundir esquemas visuales, en el día a día, y de responder infográficamente a un aconte- 
cimiento inesperado es una consecuencia directa de los avances informáticos ${ }^{1}$, sin mencionar el cambio que ha supuesto Internet y la World Wide Web. Los gráficos ahora se leen, se oyen, se miran, se ven, se animan, se interactúan y se personalizan. El entorno digital proporciona una comunicación iconográfica multisensorial.

En la breve historia de la infografía moderna, hay que situar la relevancia que tuvo para su despegue la primera Guerra del Golfo. En enero de 1991, los rotativos españoles y las agencias de información desplegaron todos sus efectivos, humanos y técnicos, para contar a sus lectores, de una forma gráfica, una contienda de la que no había imágenes, salvo las ofrecida por la cadena de televisión, $C N N$. La necesidad de mostrar lo que sucedía en Iraq fue una circunstancia que contribuyó poderosamente a su desarrollo, propiciando la elaboración de crónicas y relatos en los que se descubrían al detalle cualquier objeto bélico. Fue también el momento de los megagráficos, reportajes que podían ocupar una o dos páginas, según la información de la que se disponía en las redacciones.

El uso de un gráfico, de un plano o de un mapa, en el entorno informativo, no es una aportación novedosa. Dibujos explicativos y divulgativos se han utilizado, de muy diversas maneras, a lo largo de la historia. Los esquemas científicos, la imagen o ilustración documental, son tan antiguos como la escritura. Las pinturas rupestres, las tabletas de arcilla, los pictogramas o los jeroglíficos ofrecían un cúmulo de información sobre el desarrollo de las civilizaciones primitivas. Los cantares de ciego, con su combinación de imagen y voz, servían como vehículo de difusión de sucesos varios. Las "biblias de los pobres" facilitaron a la iglesia la expansión del contenido de los libros sagrados a un pueblo que no sabía leer. Las técnicas de grabación, los tipos móviles y la aparición de las primeras publicaciones noticiosas fueron impulsando el incremento continuo e incesante de la producción icónica. Y estos materiales o documentos son también los orígenes de la ciencia de la documentación.

El relato infográfico es esencialmente realista. Impera la inteligibilidad del mensaje, focalizada en la evidencia informativa, en su monosemia, en su concreción y transparencia, convirtiendo los datos complejos o abstractos en asequibles. La imagen, en este contexto, se aleja de la imprecisión para que la comunicación sea efectiva. La infografía participa de la mezcla de lenguajes. Es una combinación de texto, imagen -fija, animada o en movimiento- sonido o vídeo, dependiendo del canal utilizado. Requiere un mensaje comprensible, que facilite las claves del acontecimiento que transmite, con una estructura narrativa que clarifique, rebele o explique los datos. Es una forma visual de contar la actualidad, de modelar gráficamente un contenido, no para cubrir huecos, y sí para comunicar. La confluencia entre texto e imagen, entre forma y función, entre contenido y estructura es la dimensión vehicular de la actividad gráfica. Como cualquiera de los otros géneros informativos, se contempla bajo una es-

${ }^{1}$ El ordenador portátil, PC, aparece en agosto de 1981 y Macintosh lo hace en 1984. La popular máquina de Steve Jobs y Stephen Wozniak se introdujo con rapidez en las redacciones de los medios, convirtiéndose en el instrumento con el que desarrollar los aspectos de diseño y tratamiento de imagen. 
tructura típica, enmarcada dentro de unos rasgos similares al resto de las modalidades expresivas que caracterizan el proceso productivo de los medios. Al afrontar el análisis de esta representación gráfica, hay que tener en cuenta la dimensión icónica del constructo infográfico. La imagen confiere, a esta suerte de relato, la base sustancial de su idiosincrasia y condiciona la selección y la materialización de los datos en el mensaje final. La presentación iconográfica exige un alto nivel de iconocidad y una modelización inequívoca para que la percepción visual desemboque en una decodificación exacta del contenido. La realización de este tipo de mensaje escripto-visual, en palabras de Abraham MoLes (1990: 157), desemboca en dos maneras de codificación. Una, la textual, basada en la retórica de lo escrito y otra, icónica, que exige determinar que imágenes se pondrán, dónde, en qué momento y por qué. Esa diferencia establece una dinámica de trabajo en la que se supone un conocimiento de la información y sus posibles alternativas, más fidedigno y sintético, por una razón concluyente, la necesidad de contar visualmente. El juego de lenguajes marca la realización y delimita la integración de los mismos. La confluencia de signos lingüísticos y paralingüísticos (VERÓN, 1971: 146-147) determina la eficacia del universo infográfico. Esta diferencia en la presentación del texto se nutre, al mismo tiempo, de otras singularidades que identifican la práctica periodística.

En la materialización del documento gráfico se resalta su condición de periodismo. Se alude a los fundamentos del lenguaje informativo, como la claridad, la concisión y la brevedad. Se insiste en una exposición textual clara, ajustada a las referencias específicas y caracterizada por la precisión de las distintas vertientes del contenido, y se expresa la relevancia de la imagen como elemento índex en esa estructura escrita y visual. La materia prima es el dato y el deseo de convertirlo en visible, manejable, reconocible e interpretable. De esta forma, como elementos objetivos que son, permiten explicar, representar, mapear los rasgos que subyacen en los acontecimientos que desembocan, bajo el formato de representación visual, en las páginas de la prensa. Datos, tendencias, patrones y relaciones son el armazón al que los infografistas van a dar sentido para que se produzca el acto final de la comunicación. Su tarea parte de la identificación y continúa con la destreza de moldear y presentar el asunto en un escenario visual, en un discurso escrito-visual que responda a las necesidades informativas del lector, que se convierte en una experiencia de usuario. La narración iconográfica debería accionar la comprensión rápida y eficaz de la información: “[...] a través de la infografía se pudo conocer la tragedia ecológica que se propago a lo largo de la costa gallega como consecuencia del hundimiento de un petrolero monocasco. $42^{\circ} 12.5 \mathrm{~N} 12^{\circ} 3^{\prime} \mathrm{W}$ sólo se puede entender de forma visual. Son las coordenadas exactas del lugar de la tragedia del Prestige, el 19 de noviembre de 2002. Un punto en un plano" (OTERo y GONZÁLEZ VeIRA, 2004: 309).

El periodista visual tiene la responsabilidad de narrar un suceso, explicar un proceso y presentar los asuntos de forma precisa, comprensible y veraz: "El diseñador de información es, como diría MoLES, un «demiurgo modesto» que transforma la realidad de los fenómenos -en sí mismos tan complejos y abstractos- en otra realidad inteligible y clara, aquella que el visualista y el esquematista muestran a través de la superficie de la página impresa, o de la página electrónica" (CosTA, 1998: 22). El di- 
seño de la información, en palabras de Paul MiJKSEnAAR (2001: 51), comienza cuando se comprende e interpreta. Una opinión que comparte con Ernst GOMBRICH (2003: 230) cuando escribe sobre lo que denomina «género de instrucción gráfica»: "El ilustrador debe aprender a aislar cada una de las fases y mostrar su ejecución desde el ángulo más revelador [...]. Debe descomponer una secuencia predeterminada de posiciones estáticas o flujo continuo de un movimiento correctamente ejecutado".

El poder del mensaje anida en una representación escrito-visual de objetos, relaciones, procesos, implicaciones que configuran un desafío a la interpretación del lector que coopera e interacciona dando significado al enunciado, siempre que se establezca realmente el diálogo, siempre que se cumpla la perspectiva hermenéutica del texto. El diseño de un esquema es una cuestión de conocimiento de la clave noticiosa, de fijar el núcleo, investigando, para a continuación organizar los elementos, situarlos en un contexto, buscar la visualización material de la historia, simplificando e integrando las piezas, para crear diferentes planos de lectura.

Desde el ámbito eminentemente informativo, los infográficos, gráficos o esquemas se convierten en estructuras cuyos ítems básicos se asemejan con la forma de presentación básica de la noticia. Así, incluyen un título identificador del conjunto de datos noticiosos, con un matiz enunciativo o descriptivo que engloba lo que se expone; el texto que representa los asuntos seleccionados para la comprensión del gráfico; el cuerpo que recoge la transformación visual de la información; la fuente que identifica el origen de los datos, y el crédito que registra los nombres de las personas que han participado en la elaboración. Sin olvidar, en esa estructura, la propia materia prima, la información misma que requiere selección y organización y, porque no, el tiempo para conseguir una construcción rigurosa y clara. Todo ello conforma la unidad infográfica, que, en definitiva, la aproximan al concepto formal de noticia.

Un papel primordial en el discurso noticioso lo acaparan las fuentes y su identificación. Son un instrumento importante en el proceso productivo de la noticia y en el análisis de la profesionalidad de los periodistas: "El nexo entre acontecimiento-fuentenoticia es central en la construcción de la realidad periodística" (RodRIGO ALSINA, 2005: 181). Son el punto de partida y parte integrante del trabajo en las redacciones y en cualquier tipo de investigación. Aportan los recursos a partir de los que se arma y difunde la información y se amplía el conocimiento. La dimensión cognitiva que subyace en una noticia de calidad, identificando esa condición con la precisión de los datos manejados, tiene mucho que ver con la propia significación de la fuente $\mathrm{y}$, al final, con la credibilidad con la que el lector recibe la noticia, según NúÑEZ LADEVÉZE (1991: 285), que incide en la importancia de buscar siempre el referente original y mencionarlo claramente: "Siempre será preferible un testigo ocular que un testigo indirecto, siempre será mejor un documento original que una fotocopia. De aquí, por tanto que el periodista tenga que incluir siempre como un dato complementario de la información que suministra, la referencia a la clase de fuente". Y esas fuentes de información son de muy diversa índole. Desde el propio periodista convertido en testigo directo del suceso -una situación poco habitual-, pasando por otras personas que lo han presenciado o son protagonistas y ofrecen su punto de vista, hasta fuentes de carácter documental -libros, publicaciones, informes, etc.- dónde encontrar el material que sa- 
tisfaga las necesidades informativas de contextualización. Los medios, los periodistas deberían actuar con el objetivo de suministrar noticias pertinentes e información contextual sobre los acontecimientos en los que fijan su atención y esos contenidos que difunden tendrían que estar marcados por la exactitud, la honestidad y que sean completos, englobando todas las perspectivas para conseguir equilibrio e imparcialidad (MCQuAIL, 2000: 233-234).

Esta realidad está presente también en la información infográfica, aunque de distinta manera. Los gráficos, salvo en situaciones excepcionales, y al igual que sucede con la fotografía, forman parte de la noticia, pero esa dependencia estructural no significa que el tratamiento de los contenidos y de las fuentes tenga que ser idéntico al texto. De hecho, la propia característica de los datos que conforman el relato infográfico y su código icónico, establecen una distinción sustancial con las fuentes que se pueden manejar en la información. La profusión de referencias estadísticas y la explicación de procesos y funcionamiento de objetos o fenómenos obligan al uso de fuentes alejadas del ámbito de las declaraciones.

\section{Entorno y referencias teóricas}

Las manifestaciones infográficas, por lo tanto, son parte evidente del proceso de producción de la información periodística. En este ámbito, uno de los aspectos fundamentales son las fuentes que se convierten en el desencadenante de la noticia e intervienen en su desarrollo. Las fuentes, su identificación, confieren al relato noticioso credibilidad y fiabilidad. La labor informativa se enriquece en el momento en que se reconoce la procedencia de las voces o documentos sobre los que giran los datos transmitidos: "Es noticia' aquello que proviene de fuentes conocidas y 'fiables' y que, en cierto sentido, es ya conocido ('old news', dicen irónicamente los ingleses) porque se refiere al orden del discurso que el medio está en disposición de captar, codificar y comunicar" (CESAREO, 1986: 16). La mayor parte de los autores que han ahondado en el análisis de las fuentes están de acuerdo en que su estructuración y mención son de suma importancia para el sistema de la información. Gaye TUCHMAN (1983), Herbert Strentz (1983), Giovanni Cesareo (1986), Villafañe, Bustamante y Prado (1987), Montse Quesada (1987), Josep María Casasús (1988), Héctor BoRRAT (1989, 2006), NúÑEZ LAdEVÉZE (1991), CAMinos MARCET (1997), ARMENTia Vizuete y CAminos Marcet $(1998,2002)$, MARTínez-Fresneda Osorio (2004), RoDRIGO AlSINA (2005) y Mar de FonTCUBERTA (2011), entre otros, han abordado la relevancia, las tipologías, los efectos y funciones de las fuentes en el ámbito del periodismo. Las coincidencias entre unos y otros son evidentes. La elección y uso de las fuentes es la clave de la tarea periodística. Fuente y periodista se retroalimentan, impulsados por intereses o expectativas diferentes. Se mueven en el ámbito de la necesidad: "La fuente sería el marco con la función de recursos y construcción, al mismo tiempo, a la cual el periodista recurre con diversas intencionalidades para concretar su competencia contextualizadota del acontecimiento-noticia (RodRIGO AlsinA, 2005:185). La red de fuentes es también una forma en la que los periodistas plasman eficazmente su capacidad de búsqueda y recuperación de datos así como su posición de relevancia jerárquica. Es decir, saben como moverse en el intrincado mundo de la 
documentación y poseen todo un abanico de posibilidades que refuerza su imagen profesional: "Al conocer suficientes fuentes, los periodistas pueden lograr los máximos resultados de su capacidad para acumular un relato por día y demostrar así su competencia [...]. Cuanto más alto sea el status de las fuentes y cuanto mayor el alcance de sus posiciones, tanto más alto es el status de los reporteros" (TUCHMAN, 1983:81). Pero también los mismos investigadores hablan del juego de intereses en el que están inmersas las fuentes y la selección de las mismas que está muy lejos de ser casual. Las fuentes, con la necesidad de venderse a través de la difusión de los medios, buscan la manera de interferir en el proceso productivo de la información convertida en noticia. De ahí que, según Lorenzo GomIs (1991: 63), la responsabilidad de los medios se centra en verificar y contrastar el hecho que significa interrogarse sobre a quién se beneficia y a quién se perjudica, de tal manera que la interpretación de la noticia se hace más eficaz al poder comprobar las ventajas e inconvenientes y así identificar la verdadera fuente.

Las claves del análisis del papel de las fuentes infieren un discurso de parecidos rasgos. Sin embargo, en el apartado taxonómico, aún existiendo términos o denominaciones comunes, los diferentes autores enumeran tipologías más o menos exhaustivas, que sintetizan, en unos casos, o amplían, en otros, propuestas anteriores. Sin embargo, a pesar de las diferencias entre los catálogos de fuentes, existen bastantes similitudes. De hecho, la mayor parte de los autores hablan de fuentes procedentes del entorno público, dónde encuadran a las instituciones y organismos gubernamentales; para contraponer el apartado de fuentes no gubernamentales, que incluiría todo el abanico del entorno privado, desde empresas, asociaciones, organizaciones, federaciones, etc. En algunos casos, también se mencionan como un tipo específico, las fuentes informativas o de medios de comunicación, así como las fuentes documentales que constituyen una amplia gama de recursos y, como no, los medios e instrumentos que han puesto al alcance del periodista, y de cualquier usuario, Internet y la World Wide Web, con un casi incalculable número de sitios, unos más visibles -la red de fuentes habitualesy otro algo menos visible -la denominada Internet invisible, conformada por recursos muy especializados como bases de datos o publicaciones expertas-.

\begin{tabular}{|c|c|}
\hline Autoría & Taxonomías de fuentes \\
\hline $\begin{array}{l}\text { STRENTZ } \\
\quad(1983: 107-134)\end{array}$ & $\begin{array}{l}\text { Fuentes noticiosas tradicionales: fuentes informativas oficiales o de ru- } \\
\text { tina, relaciones públicas o agencias y personal de promoción, presen- } \\
\text { cia del periodista en el acontecimiento (a las que confiere la } \\
\text { característica de previsibles y continuas). } \\
\text { Fuentes noticiosas no tradicionales: métodos del periodismo de preci- } \\
\text { sión; archivos públicos y promulgación y leyes sobre libertad de in- } \\
\text { formación; fuentes anónimas o veladas y grupos minoritarios }\end{array}$ \\
\hline $\begin{array}{l}\text { CESAREO } \\
\text { (1986: 69-77) }\end{array}$ & $\begin{array}{l}\text { Protagonistas y testigos, fuentes primarias } \\
\text { Centros de carácter documental } \\
\text { Fuentes definidas (agencias, empresas, etc.) } \\
\text { Fuentes institucionales } \\
\text { Fuentes activas (fuentes estables centrales y fuentes estables territoriales) } \\
\text { Fuentes pasivas (fuentes estables territoriales y fuentes de base o even- } \\
\text { tuales) }\end{array}$ \\
\hline
\end{tabular}




\begin{tabular}{|c|c|}
\hline Autoría & Taxonomías de fuentes \\
\hline $\begin{array}{l}\text { VILLAFAÑE, BUSTA- } \\
\text { MANTE, PRADO } \\
\text { (1987: } 56)\end{array}$ & $\begin{array}{l}\text { Centros regionales } \\
\text { Corresponsales y reporteros } \\
\text { Documentación y agenda del medio } \\
\text { Fuentes gubernamentales } \\
\text { Patronales } \\
\text { Sindicales } \\
\text { Partidos políticos } \\
\text { Organizaciones sociales } \\
\text { Expertos } \\
\text { Testimonios } \\
\text { Agencias } \\
\text { Otros medios de información } \\
\text { Otras fuentes }\end{array}$ \\
\hline $\begin{array}{l}\text { QUESADA } \\
\qquad(1987: 97-98)\end{array}$ & $\begin{array}{l}\text { Fuentes escritas: archivos, libros, textos o textos de libre consulta y es- } \\
\text { critos en general o documentación varia. } \\
\text { Fuentes orales: oficiales y extraoficiales u oficiosas }\end{array}$ \\
\hline $\begin{array}{l}\text { CASASÚS } \\
\qquad(1988: 133-134)\end{array}$ & $\begin{array}{l}\text { Recursos personales y fuentes propias: } \\
\text { Pasivos: observación directa o fortuita, escucha no sistemática y lec- } \\
\text { tura contingente } \\
\text { Activos y tres métodos de trabajo: investigación (reconstrucción teó- } \\
\text { rica de los hechos, redes de confidentes o de informadores no profe- } \\
\text { sionales, análisis de documentos e indagación en archivos, registros y } \\
\text { protocolos), entrevistas técnicas (múltiples o encuestas, inopinadas, } \\
\text { solicitadas o concertadas u ofrecidas) y documentación (bancos de } \\
\text { datos, archivos, libros, hemerotecas, bibliotecas, etc.) } \\
\text { Personales: propias del periodista } \\
\text { Fuentes genéricas y convencionales, estables u organizadas: agencias, } \\
\text { gabinetes, vaciado periódicos, revistas, boletines, publicaciones, etc. } \\
\text { Fuentes específicas y eventuales: protagonistas de los hechos y testigos } \\
\text { presenciales, organismos públicos, organizaciones políticas, sindica- } \\
\text { les, económicas, culturales, deportivas; asociaciones privadas, empre- } \\
\text { sas y personalidades influyentes. }\end{array}$ \\
\hline $\begin{array}{l}\text { BORRAT } \\
\quad(1989: 59-60)\end{array}$ & $\begin{array}{l}\text { Fuentes gubernamentales, oficiales u oficiosas } \\
\text { Fuentes no gubernamentales } \\
\text { Fuentes centrales y territoriales } \\
\text { Fuentes primarias y secundarias }\end{array}$ \\
\hline $\begin{array}{l}\text { RESNAY } \\
\quad(1989 \text {, cit. DEL VALLE, } \\
\text { Carlos, 2005: 2) })^{2}\end{array}$ & $\begin{array}{l}\text { Fuentes regulares } \\
\text { Fuentes específicas } \\
\text { Fuentes circunstanciales } \\
\text { Fuentes documentales }\end{array}$ \\
\hline
\end{tabular}

${ }^{2}$ Carlos DEL VALLE recoge la tipología de fuentes aportada por el autor francés Joël Resnay en $L$ 'avenier en direct, una propuesta que aparece en el manual Periodismo Científico y Educativo (1974), publicado, en Bogotá, por el Centro Interamericano para la Producción de Material Educativo y Científico para la Prensa (CIMPEC), según Marisa Avogadro, y del que existe una reedición del Fondo Editorial de CIESPAL, Quito, 1976, según Diana CAZAUX. 


\begin{tabular}{|c|c|}
\hline Autoría & Taxonomías de fuentes \\
\hline $\begin{array}{l}\text { CARRIZO SAINERO } \\
(1994: 38)\end{array}$ & $\begin{array}{l}\text { Fuentes documentales } \\
\text { Fuentes bibliográficas: } \\
\text { Según soporte (impresos, audiovisuales y mecanizadas) } \\
\text { Según acceso al contenido (información inmediata, puntual o precisa; } \\
\text { información mediata o diferida; información largamente diferida) } \\
\text { Según nivel de información (fuentes primarias, secundarias, terciarias, } \\
\text { obras de referencia o consulta) } \\
\text { Según la facilidad de acceso (publicadas, inéditas, reservadas) }\end{array}$ \\
\hline $\begin{array}{l}\text { CAMINOS MARCET } \\
\text { (1997: 173-179) }\end{array}$ & $\begin{array}{l}\text { Fuentes personales } \\
\text { Según la duración de la relación periodista-fuente: estables y provisio- } \\
\text { nales } \\
\text { Según la posición e la fuente: públicas, privadas, confidenciales y ex- } \\
\text { pertas } \\
\text { Según la actitud de la fuente: activas o espontáneas (ávidas y compulsi- } \\
\text { vas), pasivas (resistente y abierta) } \\
\text { Fuentes documentales o escritas: archivos, textos de libre consulta, do- } \\
\text { cumentación varia, bancos de datos. } \\
\text { Fuentes gubernamentales y no gubernamentales }\end{array}$ \\
\hline $\begin{array}{l}\text { ARMENTIA VIZUETE y } \\
\text { CAMINOS MARCET } \\
(1998: 251-266)\end{array}$ & $\begin{array}{l}\text { Fuentes personales: } \\
\text { Según la duración de la relación periodista-fuente: estables y provisio- } \\
\text { nales } \\
\text { Según la posición de la fuente: públicas, privadas, confidenciales y ex- } \\
\text { pertas. } \\
\text { Según representatividad de la fuente: gubernamentales y no guberna- } \\
\text { mentales } \\
\text { Según alcance de la información que suministran: fuentes centrales y } \\
\text { territoriales } \\
\text { Fuentes habituales o comunes: agencias de información, medios de co- } \\
\text { municación, archivos, gabinetes, rueda de prensa, fuentes propias }\end{array}$ \\
\hline $\begin{array}{l}\text { ARMENTIA ViZUETE y } \\
\text { CAMINOS MARCET } \\
\text { (2002: 107-120) }\end{array}$ & $\begin{array}{l}\text { Fuentes personales: } \\
\text { públicas, privadas, expertas, gubernamentales, no gubernamentales, } \\
\text { centrales y territoriales } \\
\text { Fuentes documentales o escritas (documentos públicos, documentos } \\
\text { secretos), archivos, textos de libre consulta, documentación varia, } \\
\text { bancos de datos } \\
\text { Fuentes habituales: agencias, medios, archivos, gabinetes, ruedas de } \\
\text { prensa, internet... }\end{array}$ \\
\hline $\begin{array}{l}\text { SOENGAS } \\
\quad(2003: 106-109)\end{array}$ & $\begin{array}{l}\text { Según la relación de la persona con los hechos: directas o primarias, in- } \\
\text { directas o secundarias } \\
\text { Según la procedencia de los datos: fuentes institucionales o públicas, } \\
\text { fuentes privadas } \\
\text { Según mecanismos de acceso a la información: legítimas e ilegítimas } \\
\text { Archivos }\end{array}$ \\
\hline
\end{tabular}




\begin{tabular}{|c|c|}
\hline Autoría & Taxonomías de fuentes \\
\hline $\begin{array}{l}\text { MARTíNEZ-FRESNEDA } \\
\text { OSORIO } \\
\text { (2004: 266-267) }\end{array}$ & $\begin{array}{l}\text { Fuentes de información personales: } \\
\text { Periodísticas - gabinetes de prensa, medios de comunicación, agencias } \\
\text { de información- } \\
\text { No periodísticas - anónimas, confidenciales- } \\
\text { De desinformación -rumor y filtración- } \\
\text { Secreto profesional } \\
\text { Fuentes de información documentales: } \\
\text { Manuales de referencia - diccionarios, directorios, enciclopedias, anua- } \\
\text { rios, estadísticas, biografías, cronologías, repertorios de medios de } \\
\text { comunicación- } \\
\text { Bases de datos (y recursos on-line) -numéricas, bibliográficas, directo- } \\
\text { rios, portales de información para periodistas- } \\
\text { Audiovisuales - fotografías, imágenes en movimiento, archivo sonoro- } \\
\text { Revistas especializadas }\end{array}$ \\
\hline $\begin{array}{l}\text { MAYORAL SÁNCHEZ } \\
(2005,96)\end{array}$ & $\begin{array}{l}\text { Intermediarios o agencias informativas } \\
\text { Fuentes oficiales (gobierno central, gobiernos autonómicos, ayunta- } \\
\text { mientos, sindicatos, partidos políticos, patronal, otras instituciones y } \\
\text { otros) } \\
\text { Fuentes no oficiales (asociaciones, organizaciones no gubernamentales, } \\
\text { expertos, miembros de instituciones u organismos, otros) }\end{array}$ \\
\hline $\begin{array}{l}\text { RoDRIGO ALSINA } \\
\quad(2005: 192-194)\end{array}$ & $\begin{array}{l}\text { Fuentes institucionales } \\
\text { Fuentes de rutina o habituales } \\
\text { Fuentes no habituales o no rutinarias } \\
\text { Fuentes alternativas } \\
\text { Fuentes utilizadas. Producción } \\
\text { Fuentes mencionadas. Manifestación }\end{array}$ \\
\hline $\begin{array}{l}\text { BORRAT } \\
\quad(2006: 245-246)\end{array}$ & $\begin{array}{l}\text { Fuentes identificadas }- \text { veladas }- \text { anónimas }- \text { omitidas } \\
\text { Fuentes activas - reactivas } \\
\text { Fuentes primarias }- \text { secundarias } \\
\text { Fuentes profesionales }- \text { no profesionales } \\
\text { Fuentes recuentes - ocasionales }\end{array}$ \\
\hline $\begin{array}{l}\text { DÍAZ ARIAS } \\
\quad(2008: 161)\end{array}$ & $\begin{array}{l}\text { Fuentes personales y fuentes documentales } \\
\text { Fuentes primarias o directas y fuentes secundarias o indirectas } \\
\text { Fuentes propias y ajenas }\end{array}$ \\
\hline $\begin{array}{l}\text { FONTCUBERTA } \\
(2011: 77-78)\end{array}$ & $\begin{array}{l}\text { Fuentes exclusivas (propias) y fuentes compartidas (agencias, gabine- } \\
\text { tes, comunicados, conferencias de prensa, etc.) } \\
\text { Según la actitud de la fuente: fuente resistente, abierta, espontánea, } \\
\text { ávida, compulsiva } \\
\text { Según el grado de intervención del periodista: fuente de primera mano, } \\
\text { de segunda mano y de tercera mano }\end{array}$ \\
\hline
\end{tabular}

En definitiva, fuente es cualquier persona, material o producto, original o elaborado, que suministre informaciones o datos que se puedan utilizar como testimonios de acceso al conocimiento; es todo aquello que facilite la provisión de información para luego transmitirla (CARRIZO, 1994: 30). Su función informativa abarca el proceso de verificación, la aportación de antecedentes y la identificación del contexto que convierten a la noticia y al relato infográfico en mensajes con relieve. 


\section{Apuntes metodológicos}

El objetivo del análisis es identificar, catalogar y comprobar el tipo de fuentes que se mencionan en los infográficos, de forma general y por cada periódico estudiado. Se trata de verificar la presencia y/o ausencia de las mismas, relacionando el tratamiento con los asuntos abordados en los gráficos. La infografía, que ocupa su espacio en las páginas de los rotativos, se sitúa dentro del entorno de la información y se nutre de datos que, no siempre, reproducen los contenidos de las noticias que acompaña. Por eso, las unidades infográficas pueden contar con sus propias fuentes, por la misma dimensión documental en la que se insertan los elementos informativos. A pesar de ello, el origen de los datos, hipótesis de partida del trabajo, proceden mayoritariamente de fuentes gubernamentales y organismos públicos. Mientras que se produce un mayor número de atribuciones como consecuencia del carácter tan específico de la información utilizada, las cifras.

Para desenvolver la tarea, se ha optado por la técnica del análisis de contenido, encuadrada en el método cuantitativo. Se ha elaborado una ficha de recogida de datos en la que aparecen distintos campos como: nombre del diario, fecha, sección, contenido de la noticia, contenido del infográfico, fuente y firma. Esta estructura tendría que servir para fijar los aspectos que se incorporan al construir los gráficos y permitir la cuantificación pero también el establecimiento de relaciones entre registros con la finalidad de alcanzar los objetivos y responder a la hipótesis.

Las distintas tipologías, ya avanzadas, guardan bastantes relaciones entre sí. Se evidencia cierta dimensión de retroalimentación entre las distintas exposiciones. En algunos casos, se incluyen, como sustantivas dentro del método de trabajo informativo, los instrumentos documentales, las aportaciones informativas entresacadas de materiales escritos que aportan en general datos específicos, muchas veces, numéricos. La utilización de estadísticas, informes, estudios y análisis, elaborados desde diversos ámbitos de la investigación, es un elemento sustancial a la hora de configurar las noticias. La documentación informativa, según FuenTES I Pujol (1997: 87), es la aplicación de métodos y técnicas documentales al entorno de la documentación. Las noticias documentadas se convierten en auténticos testimonios no sólo el presente sino también como recursos retrospectivos que se pueden reutilizar como referencias del pasado: "Una buena documentación es la base imprescindible para que la tarea informativa adquiera un buen nivel, tanto cualitativamente como cuantitativamente; [...] la documentación aplicada al ámbito de los medios de comunicación de masas sirve de intermediario entre el profesional de la información y los usuarios, y viceversa, y además es un elemento básico para elaborar nuevas informaciones" (o. cit.: 89).

Así para este trabajo se ha establecido una tipología que engloba:

- Fuentes gubernamentales públicas

- Fuentes no gubernamentales privadas

- Fuentes periodísticas o de medios de comunicación

- Fuentes documentales

- Fuentes territoriales o autonómicas e internacionales

- Fuentes digitales

- Elaboración propia 
Este corolario permitió identificar la red de fuentes consignadas en los infográficos. Las categorías forman parte de las diversas aportaciones de los investigadores que han estudiado el asunto en el ámbito periodístico. Las fuentes gubernamentales abarcan todo el abanico de instituciones que conforman la estructura de gobierno, tanto ministerios como organismos o empresas públicas que se adscriben bajo su jurisdicción. Mientras que todo el espectro de fuentes privadas se enmarcan dentro del epígrafe no gubernamental. Forman parte de esta clasificación empresas, entidades financieras, sindicatos, partidos, entidades educativas o judiciales, asociaciones ciudadanas y cualquier entidad que, funcionalmente, se sitúe al margen de los gobiernos. Las fuentes periodísticas son aquellas que, de forma usual, están presentes en las rutinas productivas. Agencias de noticias y otros medios de comunicación, tanto centrales y autonómicos como extranjeros se insertan en esta denominación. La perspectiva geográfica se ha ampliado con el objetivo de delimitar la presencia de instituciones y organismos exteriores, tanto públicos como privados, en el marco de la mundialización comunicativo-informativa y se mantiene la proyección territorial, dónde se enmarcan las voces, tanto gubernamentales como no gubernamentales, que trabajan en el ámbito autonómico. La irrupción de fuentes digitales, ya incorporadas en alguna de las taxonomías, implica el reconocimiento y el incremento de recursos accesibles, actualizables, variados y almacenados para su uso en cualquier momento, en cualquier idioma y sin cambiar la posición frente al ordenador. Se ha optado por mantener esta categoría en la medida que en la World Wide Web, independientemente de proveer información, los sitios web tienen características diferenciadoras, dependiendo de la estructura, el tratamiento o el acceso a los contenidos. A pesar de la perspectiva delimitadora, en este apartado se incorporan las menciones de URLs. Las fuentes documentales representan la dimensión contextualizadora y la diferenciación que se puede entrever entre noticias textuales y noticias infográficas, ya que estas últimas buscan completar y ensanchar el discurso informativo de aquellas. Libros, publicaciones especializadas, archivos o bases de datos son algunas de los instrumentos que identifican el aspecto documental, junto al papel que desempeñan los centros de documentación de los propios diarios con sus aportaciones expertas a la labor informativa. Por último, la inclusión de la categoría "elaboración propia" responde a una práctica habitual en los periódicos y que se convierte en un terreno indefinido y muy abierto, donde se implica al propio medio como origen, aunque los datos dejen vislumbrar, a veces, una procedencia equívoca, por su idiosincrasia. La idea de elaboración propia parece consecuente cuando lo difundido se desprende de una tarea científico-investigadora y no de un esfuerzo recopilador. En el plano de los gráficos, la índole de los datos con los que se suele trabajar, modifica la perspectiva de ese tipo de mención. La mayor parte de los contenidos que se manifiestan bajo aquella denominación son estadísticos. Esta condición expresa de las referencias, salvo un trabajo propio del medio, requerirían una clara identificación. Un suceso, como un accidente de circulación, podría delimitarse como elaboración propia en la medida en que la información puede proceder del redactor encargado del asunto e, incluso, de la intervención del infografista para recabar los elementos informativos que necesitaría para construir un relato donde lo visual tiene una significación comunicativa. 
Se han seleccionado cinco periódicos. Cuatro, de ámbito español, de los que uno de ellos tiene edición para Galicia, y uno gallego. La elección de $A B C$ (1905), El Mundo (1989), El País (1976), Público (2007) y La Voz de Galicia (1882) ${ }^{3}$ responde al interés que esas cabeceras han prestado a la información infográfica, incorporándola poco a poco a sus páginas, que han ido adoptando pautas de modernización con cambios de diseño en su imagen y forma visual y que desde hace tiempo contaban con equipos propios de infografistas. Público, aún siendo el último en aparecer en el panorama mediático español, nació con el ideario de incorporar una amplia dimensión visual en sus páginas que lo hicieran atractivo y fácilmente legible.

\section{La gramática de los infográficos y sus fuentes}

La explosión informativa, la saturación de datos y documentos hace imposible que el profesional pueda por si solo hacen frente a esa avalancha continua de flujos noticiosos. De ahí, la cada vez mayor importancia de que los medios dispongan de un servicio de documentación estructurado y organizado, e inserto, como una referencia esencial, en el sistema productivo de la información. Estos servicios presentan tres funciones principales que van desde facilitar fuentes concretas para poder comprobar con rapidez un hecho o un dato; hasta disponer de materiales suficientes que permitan situar los distintos asuntos en su contexto; pasando incluso por ser proveedores de ideas o enfoques novedosos sobre temas que se puedan, desde la redacción, convertir en material informativo (FUENTES I PUJOL, 1995: 140).

Los medios, los profesionales precisan fuentes para difundir la noticia, pero son, al mismo tiempo, productores de información, convirtiéndose en el desarrollo de su tarea en fuentes: "Una parte fundamental de la función de estos medios es conseguir información de actualidad y una información retrospectiva, para que los profesionales de la información -los periodistas- la hagan llegar a los usuarios o lectores" (FUENTES I PuJOL, 1997: 88). Es evidente que las necesidades documentales del periodista presentan diferentes dimensiones. El grado de urgencia varía de acuerdo a dos variables, según explica Montse QuesadA (1995: 44), las características estructurales del medio, ya sea prensa, radio o televisión, y la modalidad de periodismo que desarrolle -generalista, especializado, investigación, etc.-.

Cada medio y cada tipo de periodismo condiciona e impone unas exigencias documentales diversificadas en función de como se empaquetan las noticias y los objetivos informativas de las mismas. Por lo tanto, la actividad periodística es una de las que necesita disponer de datos fiables, precisos y verificables de una forma rápida. Documentarse para completar y verificar la información que se va a difundir a través de los medios de comunicación es la necesidad constante de los redactores (PONS SERRA, 1995: 53). Una necesidad que ha amplificado los grados de complejidad documental al incorporarse toda una gama de recursos a los que se accede a través de un ordenador conectado en red a una red.

${ }^{3}$ Las fechas en las que se desarrolló el estudio fueron: enero $(9,17$ y 25$)$, mayo $(4,12,20$ y $28)$, noviembre $(6,14,23$ y 30$)$ y diciembre $(8,16$ y 24$)$ de 2009. 
Las tecnologías de la información y comunicación han propiciado la aparición de un espectacular número de fuentes que facilitan la tarea documental y que exigen un cuidado y una evaluación sistemática de los productos. Internet y la World Wide Web han puesto a disposición de los periodistas toda una amalgama de materiales digitalizados que abarcan desde obras de referencia primaria -diccionarios, enciclopedias, repertorios biográficos, guías y directorios nacionales e internacionales, atlas y anuarios geográficos- hasta una amplia gama de repertorios de libros, revistas, artículos, literatura gris, etc. (PONS SERRA, 1995: 54-76). Toda esa enorme cantidad de materiales a los que se puede acceder en el ciberespacio exige una enorme capacidad de discriminación así como la toma de precauciones para cribar los recursos a disposición de los periodistas. Las fuentes requieren examen y constante evaluación con el fin de establecer una agenda fiable y comprobable. Hay que ser un experto para entender y comprender buena parte de todo ese material. Para ello, y en palabras de Philip MEYER (1991: 26), el cuerpo de conocimientos periodísticos tiene que incluir necesariamente habilidades que van desde cómo encontrar información, cómo valorarla y analizarla hasta como transmitirla para que trascienda la amalgama de la sobrecarga informacional y llegue al público. Por lo tanto, el periodista requiere unos amplios conocimientos para discernir con precisión las fuentes exigidas por el asunto que pretende difundir. La documentación se convierte en un elemento constitutivo de la información en el entorno del periodismo. La documentación informativa o periodística engloba un proceso mediato, de carácter intelectual al poner en marcha las funciones valorativa y clasificatoria, y un proceso informativo al elaborar la noticia, que constituye el objetivo e esas tareas documentales (GALDÓN LóPEZ, 1989:5).

Tras la delimitación de las fuentes, aparece el aspecto de la mención de las mismas. La atribución determina la forma en el que el periodista desvela que la información proviene de unas fuentes determinadas. Añade una perspectiva más veraz a la noticia o al gráfico, ya que el público lector ve, en esa mención, una garantía de fidelidad a los hechos narrados (FONTCUBERTA, 2011: 78). En este caso, sólo se puede hablar de identificación directa o explícita o de ausencia. Se atribuyen los datos inequívocamente, identificando de forma clara a la persona o institución que proporciona las referencias o, por el contrario, no aparece reseñada la identidad, quedando en el anonimato. Son las dos modalidades a tener en cuenta y que se alejan de otras fórmulas que sí tienen cabida en la información escrita. Las referencias genéricas como "fuentes próximas", "fuentes judiciales", "fuentes gubernamentales", "fuentes de la investigación" o cualquiera otra variante que enmascara el origen de los datos no forma parte del proceso infográfico. Sin embargo, la modalidad "elaboración propia" se convierte en una especie de comodín indefinido que podría relacionarse, sin lugar a dudas, con la atribución genérica o reservada. Pero las cifras, por lo general, son aportaciones externas. La expresión "elaboración propia" acaba enmascarando el origen de los contenidos informativos.

En definitiva, y a pesar del grado de credibilidad que la atribución otorga al texto informativo, el uso de fuentes identificables no debiera afectar al esfuerzo de verificación que desarrolle el periodista/infografista. La veracidad de los contenidos depende de las posibilidades de comprobación o de que la fuente pueda demostrar sus aportaciones (CAMINOS MARCET, 1997: 161-162). 


\section{Las fuentes en la infografía}

Durante el periodo de análisis, en los cinco periódicos que conforman la muestra, se han contabilizado 326 noticias $^{4}$ que incluían unidades gráficas. De ese conjunto publicado, el origen de la información aparecía claramente mencionado en 225 . El anonimato o ausencia se produjo en un total de 101 piezas, lo que representa casi el 31 por ciento frente al 69 en el que sí hubo algún tipo de mención. La carencia de identificación se hizo más palpable en los rotativos $A B C$, con un total de 36, La Voz de Galicia, con 35 y El País, con 23; mientras que en Público y en El Mundo se redujo a cuatro y tres, respectivamente.
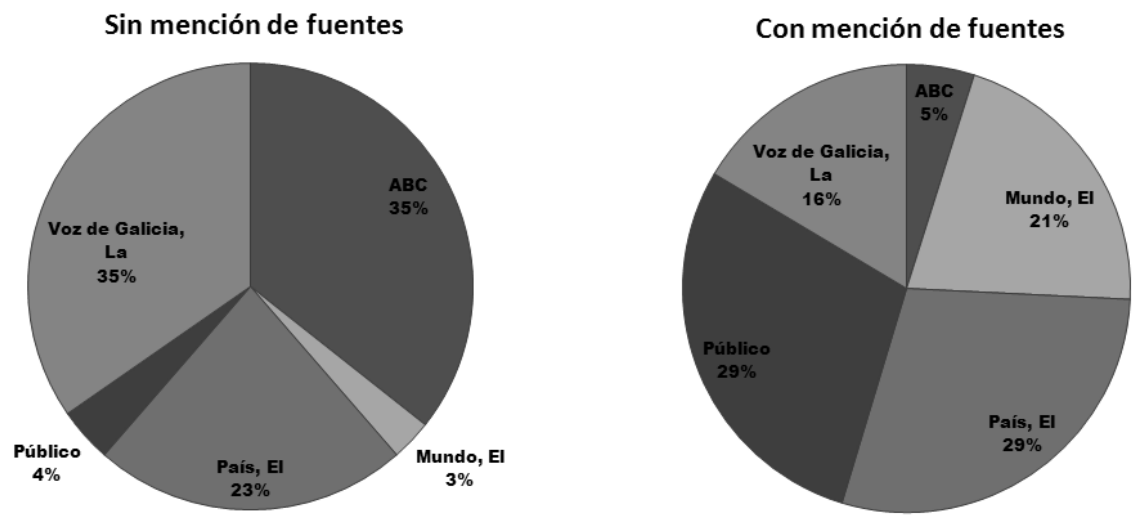

Gráficos 1 y 2. Ausencia y atribución de fuentes

Estas cifras globales deben enmarcarse dentro de las diferencias existentes en el grado de producción infográfica. Así, de las 88 noticias con gráficos que se difundieron en El País, la mayor parte, 65, presentan una clara identificación de la fuente. En La Voz de Galicia, con 72 publicadas, la atribución directa se ciñó a 37. En Público, de las 69 difundidas, sólo cuatro aparecen sin referencia específica. Esta similitud entre infografías y fuentes, también se plasmó en El Mundo, ya que de las 50 noticias, en tres no hubo mención. Este equilibrio se rompe en $A B C$, pues de las 47 informaciones, solo en 11 se ha identificado el origen.

\begin{tabular}{lcccccc}
\hline Gráficos con & $\mathrm{ABC}$ & Mundo, El & País, El & Público & Voz de Galicia, La & Totales \\
\hline 1 fuente & 9 & 27 & 43 & 52 & 34 & 165 \\
\hline 2 fuentes & 2 & 13 & 17 & 9 & 2 & 43 \\
\hline f fuentes & & 7 & 4 & 4 & 1 & 16 \\
\hline 5 fuentes & -- & - & 1 & --- & -- & 1 \\
$\begin{array}{l}\text { Total más } \\
\text { fuentes }\end{array}$ & 11 & 47 & 65 & 65 & 37 & 225 \\
$\begin{array}{l}\text { Sinfuentes } \\
\text { Noticias }\end{array}$ & 36 & 3 & 23 & 4 & 35 & 101 \\
\hline
\end{tabular}

Tabla 1. Distribución de noticias/gräficos y fuentes

${ }^{4}$ En el estudio se optó, en un primer momento, por identificar noticia e infográfico, independientemente de que, en algunos casos, en los textos informativos pudieran aparecer más de un gráfico. Sin embargo, cuando se aborde la tipología, las cifras pueden variar al establecer todas las fuentes usadas. 
En lo que respeta al número de fuentes que se recogen en cada gráfico no hay grandes sorpresas. De hecho, oscila entre una y dos, de forma generalizada. En el único diario en el que se computaron cinco fuentes en un mismo trabajo fue en El País, al abordar la situación de la prensa en España, usando referencias de tres organismos, uno público, INE y, dos privados, OJD y EGM, así como dos internacionales, Eurostat y WAN. A continuación, y en orden ascendente, aparece un total de 16 gráficos que incorporan tres fuentes; de los que siete corresponden a El Mundo; cuatro, a El País y Público, indistintamente, y uno se publicó en La Voz de Galicia. Con dos, se han contabilizado 43 unidades, de las que 17 se publicaron en El País; 13, en El Mundo; nueve, en Público, y dos, en La Voz de Galicia y en $A B C$. Por último, una única fuente es la tónica documental en el periodo de análisis y en los rotativos estudiados. De las 165 infografías que responden a esa práctica, 52 se difundieron en Público; 43, en $E l$ País; 34, en La Voz de Galicia; 27, en El Mundo, y, nueve, en ABC.

\section{Fuentes y contenidos}

La información implica una cierta dimensión investigadora. Los mensajes difundidos por los medios de comunicación suponen la búsqueda de elementos básicos, datos suministrados por fuentes que, una vez verificados y ensamblados, contribuyen, en el momento de la recepción a crear significado. La infografía, como producto informativo, se construye también para completar ese fin, usando idénticos criterios. La incorporación de las fuentes, en el proceso de elaboración, presenta una óptica más documental al ser el infográfico un instrumento que aporta o podría aportar referencias contextualizadoras. Siempre y cuando no se utilice como mero elemento decorativo. En esa función interviene el infografista con sus habilidades periodísticas e iconográficas, así como por su capacidad de selección de las fuentes adecuadas.

En los 326 gráficos analizados, se han usado un total de 192 fuentes únicas, de las que 163 han aparecido una vez y el resto se mencionaron entre dos y 15. Así, el Instituto Nacional de Estadística (INE) ha sido el organismo público que alcanzó esa cifra máxima, distribuyéndose su presencia entre las seis menciones en Público; cuatro, en El País; dos, en El Mundo y en La Voz de Galicia, y una, en ABC. Con seis alusiones menos se encuentran el órgano europeo Eurostat -tres, en Público y en El País; dos, en $E l M u n d o$, y una, en $A B C$-, agencias informativas sin especificar -seis, en $E l$ Mundo; dos, en Público, y una, en El País-, unas aportaciones que se plasmaron mayoritariamente en mapas que respondían a asuntos de ámbito internacional. También con seis atribuciones está el Ministerio de Trabajo -seis, en El País; dos, en $A B C$, y una, en El Mundo-. Con ocho aparecen el Ministerio de Economía -cuatro, en El País; tres, en Público, y una, en La Voz de Galicia- y el Banco de España -cuatro, en El País; tres, en Público, y una, en El Mundo-; con seis, se sitúan el Ministerio de Sanidad y la Oficina de Justificación de la Difusión (OJD), y, con cinco están presentes fuentes internacionales como la OMS, OCDE y la empresa de análisis e información financiera, Bloomberg.

Los números son el núcleo de gran parte de los relatos infográficos y los diagramas son la forma gráfica de mostrarlos. Los gráficos de barras, de fiebre o de tarta se convierten en el vehículo para la presentación de las cifras, un tipo de contenido que 
emerge en cualquier página del periódico, asociado a cualquier asunto de actualidad, aunque se circunscribe, con mayor profusión, en el bloque económico. Por ello, las fuentes estadísticas tienen un peso específico en las narraciones esquemáticas.

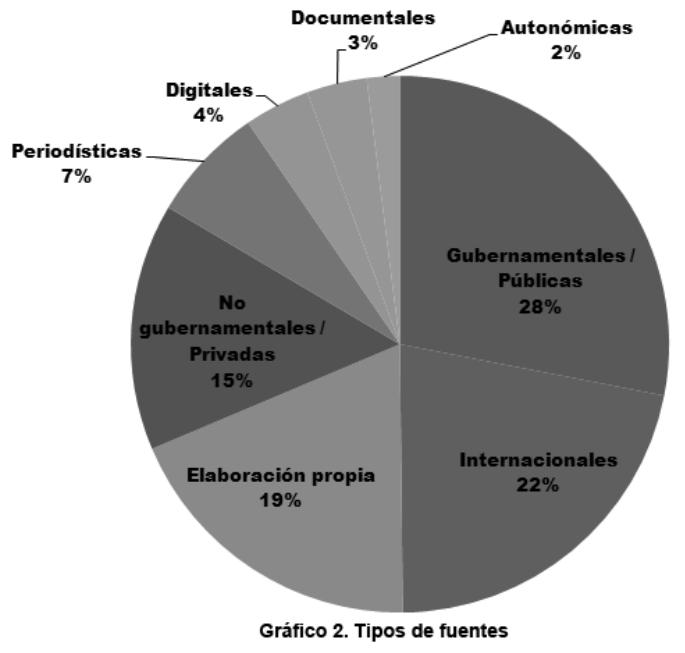

La presencia de fuentes gubernamentales ha acaparado el mayor número de menciones. De la suma global que alcanzó las 303 referencias, 85 correspondieron a departamentos y organismos que actúan en la esfera del Gobierno central. Esa cifra supone algo más del 36 por ciento en El País; casi un 32, en Público; un 13, en El Mundo; un 12, en La Voz de Galicia y un siete, en $A B C$. Por ejemplo, el término "ministerio" se ha repetido en 33 ocasiones, de las que un 45 por ciento correspondió a El País y un 21, a Público, descendiendo al 12, tanto en $A B C$ y El Mundo y, al nueve, en $L a$ Voz. El segundo puesto, con un total de 66 referencias, está ocupado por las internacionales, con mayor presencia en El País, con casi un $35 \%$. Con dos puntos menos se sitúa El Mundo y con un 21, Público; mientras que, en La Voz de Galicia y $A B C$, descienden hasta el seis y cinco \%, respectivamente. Así tras Eurostat, aparecen

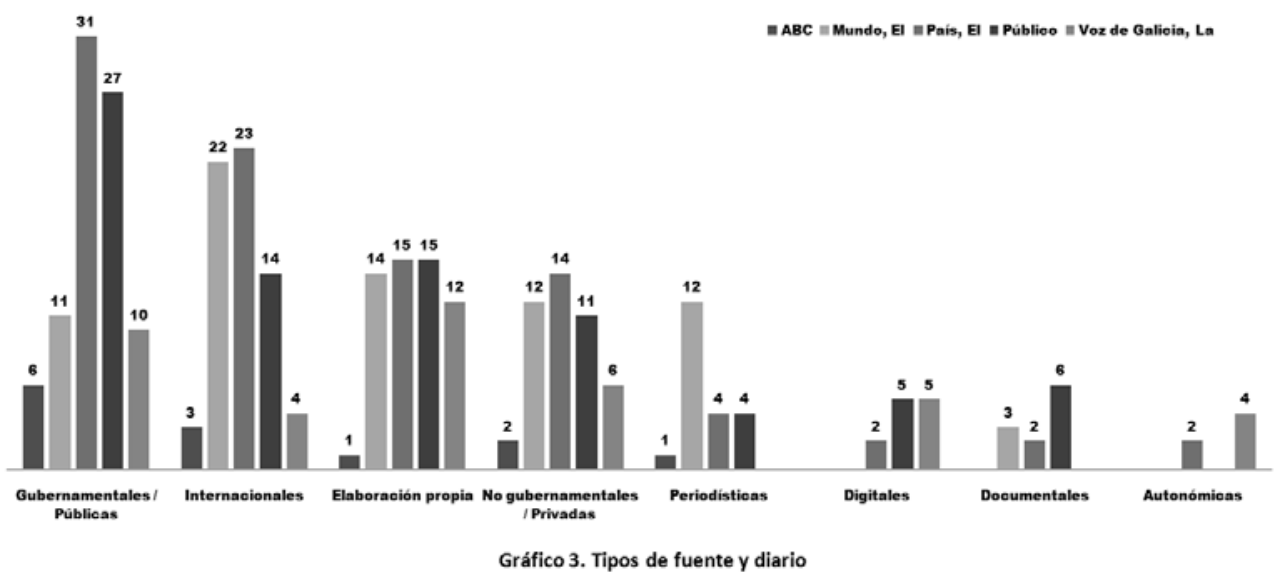


la empresa de análisis e información financiera Bloomberg, la OMS y la OCDE que suman cinco menciones cada una.

A continuación, con 57 se coloca la categoría de elaboración propia, que, en un $33,3 \%$ de las veces, está acompañada de otra fuente. En este caso, se produce cierta coincidencia entre los diarios. El País y Público suman el mismo porcentaje, un $26 \%$; con un 24,5 aparece El Mundo y con un 21, La Voz de Galicia. En ABC, representa algo menos del dos por ciento. El cuarto puesto lo ocupan las fuentes no gubernamentales. De las 45 menciones, su presencia alcanzó, en El País, el 30 \%; en El Mundo, el 27; en Público, el 25; el 14, en La Voz, y el cuatro, en $A B C$. En este caso, salvo la entidad bancaria BBVA y la empresa de estudios de mercado Sondaxe ${ }^{5}$, el resto de las fuentes del ámbito privado han aparecido una única vez. Las periodísticas se han citado un total de 21 veces. El mayor número de alusiones se produjo en El Mundo, con un $57 \%$, aunque la denominación genérica de "agencias" es la atribución más frecuente. Tras ese diario, aparecen El País y Público con un 19 \% cada uno y un cinco, en ABC. Además de la significativa repetición de la referencia "agencias", sí se identificó Reuters, en cuatro ocasiones, y el resto de medios sólo aparecieron una vez. Las fuentes digitales y documentales ocupan un espacio poco relevante. Representan el cuatro y el tres por ciento, respectivamente. Las primeras, tanto en El Mundo como en $A B C$, no tuvieron presencia. Dentro del entorno documental, sí se ha hecho mención expresa a la tarea del departamento de documentación; en El Mundo, con una cita genérica al mencionado servicio y en Público, con mención al nombre de un documentalista, mientras que en $L a V o z$ se recoge esta colaboración en el apartado de la firma. Es un pequeño reconocimiento a la importante labor que pueden desempeñar en las tareas informativas. Por último, las fuentes autonómicas tienen una presencia simbólica, con cuatro menciones en La Voz de Galicia y dos, en El País, por su edición para el territorio gallego.

\section{Conclusiones}

Las cifras son el núcleo de gran parte de los gráficos. Y si el mundo de la estadística es el eje central del periodismo iconográfico, la pauta en el entorno de las fuentes viene marcada por las instituciones, públicas y privadas, que manejan informes, estudios, investigaciones de asuntos sociales, políticos, culturales y económicos. Hay cierta dimensión de pluralidad, sin embargo la institucionalización pública domina el aporte de datos. El poder político y sus organismos son un elemento sustancial de los gráficos. La presencia de fuentes internacionales es significativa, aunque no así de la Unión Europea. Claro que también se convierte en relevante el incorporar como fuente de información la expresión elaboración propia que esconde tanto puede ocultar la fuente como la ausencia de ella.

${ }^{5}$ Sondaxe forma parte de la Corporación de La Voz de Galicia y su presencia está circunscrita al diario gallego. 


\section{Referencias bibliográficas}

ARMENTIA VIZUETE, José Ignacio y CAMINOS MARCET, José María (1998): La información: Redacción y Estructuras. Bilbao, Universidad del País Vasco.

ARMENTIA VIZUETE, José Ignacio y CAMINOS MARCET, José María (2002): Fundamentos del periodismo impreso. Barcelona, Ariel.

AVOGRADO, Marisa (2003): "Fuentes informativas y periodismo científico", en Razón y Palabra: http://www.razonypalabra.org.mx/comunicarte/2003/marzo.html [fecha de consulta: 21 de diciembre de 2011]

BORRAT, Héctor (1989): El periódico, actor político. Barcelona, Gustavo Gili.

BORRAT, Héctor (2006): "Los periódicos narradores en interacción”, en FONTCUBERTA, Mar de y BORRAT, Héctor: Periódicos: sistemas complejos, narradores en interacción. Buenos Aires, La Crujía, pp. 157-346.

CAMINOS MARCET, José María (1997): Periodismo de investigación. Teoría y Práctica. Madrid, Síntesis.

CARRIZO SAINERO, Gloria (1994): "Las fuentes de la información”, en CARRIZO SAINERO, Gloria; IRURETA-GOYENA SÁNCHEZ; Pilar, LÓPEZ de QUINTANA SÁENZ, Eugenio: Manual de fuentes de información. Madrid, CEGAL, pp. 17-44.

CASASÚS GURI, Josep M. (1988): Iniciación a la periodistica. Barcelona, Teide.

CAZAUX, Diana (2009): "El periodismo científico hoy", en Asociación de Entidades Periodisticas Argentinas (ADEPA), en: http://www.adepa.org.ar/secciones/noticias/nota.php?id=252 [fecha de consulta: 23 de diciembre de 2011]

CESAREO, Giovanni (1986): Es noticia. Barcelona, Mitre.

COSTA, Joan (1998): La esquemática. Visualizar la información. Barcelona, Paidós.

DEL VALLE, Carlos (2005): "Interculturalidad e intraculturalidad en el discurso de la prensa: cobertura y tratamiento del discurso de las fuentes en el 'conflicto indígena mapuche', desde el discurso político", en Redes.Com. Revista de Estudios para el Desarrollo Social de la Comunicación: http://www.comunicacionysaberescriticos.cl/Publicaciones/publicacion_centro_011.pdf[fecha de consulta: 17 de diciembre de 2011]

DÍAZ ARIAS, Rafael (2008): "Análisis y tratamiento de las fuentes audiovisuales". Documentación de las Ciencias de la Información, $\mathrm{n}^{\circ} 31$. Madrid, Servicio de Publicaciones de la Universidad Complutense, pp. 161-181.

FONTCUBERTA, Mar de (2011, 1993): La noticia. Pistas para entender el mundo. Barcelona, Paidós Comunicación.

FUENTES i PUJOL, M ${ }^{\mathrm{a}}$ Eulàlia (1995): "Características generales de la documentación periodística y características específicas de los medios de comunicación escrita", en FUENTES i PUJOL, M ${ }^{\text {a }}$ Eulàlia (editora): Manual de documentación periodística. Madrid, Síntesis, pp. 135-145. 
FUENTES i PUJOL, Ma Eulàlia (1997): Documentación y periodismo. Pamplona, EUNSA.

GALDÓN LÓPEZ, Gabriel (1989): Principios operativos de la documentación periodística. Madrid, Editorial Dossat.

GOMIS, Lorenzo: Teoría del periodismo. Cómo se el presente. Barcelona, Paidós Comunicación.

GOMBRICH, Ernst Hans (2003): Los usos de las imágenes. Estudios sobre la función social del arte y la comunicación visual. Barcelona, Debate.

MAYORAL SÁNCHEZ, Javier (2005): "Fuentes de información y credibilidad periodística". Estudios sobre el Mensaje Periodístico, ${ }^{\circ} 11$. Madrid, Servicio de Publicaciones de la Universidad Complutense, pp. 93-102.

MARTÍNEZ-FRESNEDA OSORIO, Humberto (2004): "Las fuentes en el periodismo informativo", en CANTAVELLA, Juan y SERRANO, Juan Francisco (coords.): Redacción para periodistas: informar e interpretar. Barcelona, Ariel, pp. 259-288.

McQUAIL, Denis (2000, 1983): Introducción a la teoría de la comunicación de masas. Barcelona, Paidós.

MEYER, Philip (1993): Periodismo de precisión. Nuevas fronteras para la investigación periodística. Barcelona, Bosch Comunicación.

MIJKSENAAR, Paul (2001): Una introducción al Diseño de la información. Barcelona, Gustavo Gili.

MOLES, Abraham (1990): "Las técnicas de la ilustración ¿cómo hacer imágenes en un conjunto?, en MOLES, Abraham y JANISZEWSKI, Luc: Grafismo funcional. Barcelona, CEAC, pp. 155-175.

NÚÑEZ LADEVÉZE, Luis (1991): Manual para periodismo. Barcelona, Ariel.

OTERO, María Luisa y GONZÁLEZ VEIRA, Xaquín (2004): “A infografía. A última incorporación á paisaxe informativa. Unhas mensaxes bimedia para mostrar o dato de noticia", en LÓPEZ, Xosé (coord.): A comunicación en Galicia 2004, Santiago de Compostela, Consello da Cultura Galega, Sección de Comunicación, pp. 309-326.

PONS SERRA, Amadeu (1995): "Fuentes de información para la actividad periodística", en FUENTES i PUJOL, $\mathrm{M}^{\mathrm{a}}$ Eulàlia (editora): Manual de documentación periodística. Madrid, Síntesis, pp. 53-88.

QUESADA, Montserrat (1987): La investigación periodística. El caso español. Barcelona, Ariel.

QUESADA Pérez, Montserrat (1995): "Necesidades documentales de la profesión de periodista", en FUENTES i PUJOL, $\mathrm{M}^{\mathrm{a}}$ Eulàlia (editora): Manual de documentación periodística. Madrid, Síntesis, pp. 43-52.

RODRIGO ALSINA, Miquel (2005): La construcción de la noticia. Barcelona, Paidós. SOENGAS, Xosé (2003): Informativos radiofónicos. Madrid, Cátedra. 
STRENTZ, Herbert (1983): Periodistas y fuentes informativas. Buenos Aires, Ediciones Marymar.

TUCHMAN, Gaye (1983): La producción de la noticia. Barcelona, Gustavo Gili.

VERÓN, Eliseo (1971): "Ideología y comunicación de masas: la semantización de la violencia política”, en VERỎ, Eliseo et al.: Lenguaje y comunicación social. Buenos Aires, Ediciones Nueva Visión, pp. 133-191.

VILLAFAÑE, Justo; BUSTAMANTE, Enrique; PRADO, Emilio (1987): Fabricar noticias. Las rutinas productivas en la radio y televisión. Barcelona, Editorial Mitre. 